\title{
A Piezoelectric Ultrasonic Linear Micromotor Using a Slotted Stator
}

\author{
Cheol-Ho Yun, Brett Watson, James Friend, Member, IEEE, and Leslie Yeo
}

\begin{abstract}
A novel ultrasonic micro linear motor that uses 1st longitudinal and 2nd bending modes, derived from a bartype stator with a rectangular slot cut through the stator length, has been proposed and designed for end-effect devices of microrobotics and bio-medical applications. The slot structure plays an important role in the motor design, and can be used not only to tune the resonance frequency of the two vibration modes but also to reduce the undesirable longitudinal coupling displacement caused by bending vibration at the end of the stator. By using finite element analysis, the optimal slot dimension to improve the driving tip motion was determined, resulting in the improvement of the motor performance. The trial linear motor, with a weight of $1.6 \mathrm{~g}$, gave a maximum driving velocity of $1.12 \mathrm{~m} / \mathrm{s}$ and a maximum driving force of 3.4 N. A maximum mechanical output power of $1.1 \mathrm{~W}$ was obtained at force of $1.63 \mathrm{~N}$ and velocity of $0.68 \mathrm{~m} / \mathrm{s}$. The output mechanical power per unit weight was $688 \mathrm{~W} / \mathrm{kg}$.
\end{abstract}

\section{INTRODUCTION}

$\mathrm{U}$ LTRASONICS and piezoelectric motors can be an attractive alternative to electromagnetic motors for end-effect devices such as microbot joints [1] and bio-medical and mobile device applications [2] because of their small size, compact structure, light weight, and high mechanical output.

For linear drive applications, many types of ultrasonic linear motors (USLM) have been developed. Among various kinds of ultrasonic linear motors, the bimodal ultrasonic linear motors using first longitudinal and second bending mode (L1B2) are well-known motors and can be driven with high output and high precision positioning [3]. Based on the construction method, USLMs can be classified into bolt-clamped Langevin transducer (BLT)type [3], [4], rectangular piezoelectric plate-type [5]-[8], and bonded metal/piezoceramic-type [9] motors.

A BLT-type USLM associated with the piezoelectric $d_{33}$ coefficients has been successfully developed with an output force of $100 \mathrm{~N}$. However, a coupling problem caused by the longitudinal motion associated with the bending mode, potentially degraded the performance of the motor [4]. This coupling problem was improved by adopting a much longer length stator [3]. However, the construction method of this BLT motor was to use several thicknesspoled lead zirconate titanate (PZT) disks sandwiched by

Manuscript received January 7, 2010; accepted April 7, 2010.

The authors are with the Micro/Nanophysics Research Laboratory, Department of Mechanical Engineering, Monash University, Clayton, Victoria, Australia.

Digital Object Identifier 10.1109/TUFFC.2010.1626 metal blocks with a bolt. This method is complex and makes assembly and size reduction difficult.

Alternatively, rectangular piezoelectric plate-type and bonded metal/piezoceramic-type USLMs using in-plane vibrations with piezoelectric $d_{31}$ coefficients can be constructed simply and at small scales. A well-known design is bimodal plate USLM developed by Nanomotion (Yokneam, Israel) [5]. This motor has one driving tip placed at one end of the stator, which transfers cyclic vibratory motion to a slider pressed against it. Other rectangular plate type USLMs with two driving tips have been developed [6], [9], which are a very attractive arrangement to save mounting space. These motors are similar in design to the Nanomotion USLM, with the exception that the piezoelectric plate is arranged lengthwise with two attached driving tips on the same length side. Two driving tips are attached to the positions of relatively higher bending displacement but not the highest longitudinal displacement position, avoiding the coupling problem of bending vibration. However, such an arrangement will prevent the maximum motor performance from being achieved.

In this paper, a novel ultrasonic linear micromotor using the 1st longitudinal and 2nd bending modes of a slotted structure is proposed. This slot structure plays an important role in motor design, which can tune the two vibration modes with same resonance frequency and decrease the undesirable longitudinal coupling displacement caused by bending vibration at the end of the stator.

\section{Construction And Operating Pricinple}

The configuration of the slotted bar-type vibrator stator for a new micro USLM is shown in Fig. 1. The stator consists of two PZT (C-213, Fuji Ceramic Co., Fujinomiya, Japan) elements and a titanium (Ti-6Al-4V, Ti64) metal bar, with a rectangular slot cut through the bar length (machined using a computer-controlled micro-electro discharge machining process, micro-EDM). The two PZT elements are bonded to the two opposite flattened sides of the metal component using an epoxy. Each PZT element has one side divided into two top electrodes with same poling directions and a uniformly formed bottom electrode which is connected to the ground. The PZT plates were polarized in the thickness directions and directions are indicated by the thick arrows in Fig. 1(a). The stator has four signal input electrodes, which are connected in diagonal pairs, to excite the vibrations. One pair of electrodes is excited as a sine input and the other pair is excited as a cosine input, as shown in Fig. 1(c). To prevent vibration 


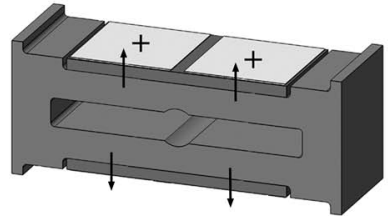

(a)

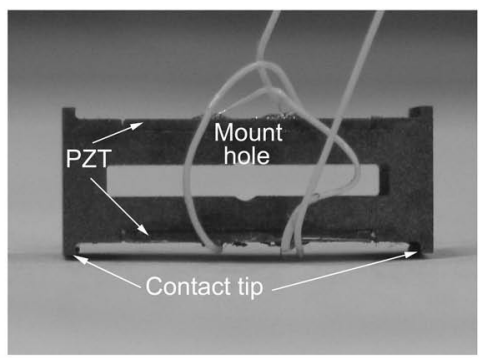

(b)

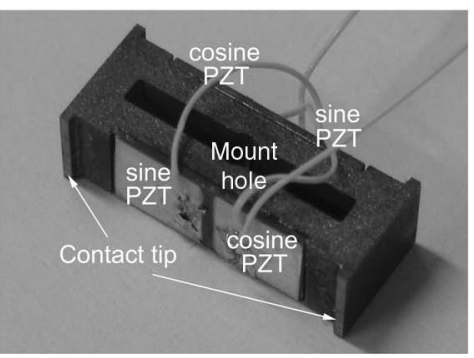

(c)

Fig. 1. The configuration of the slotted bar-type stator: (a) CAD model; and photos of a prototype (b) side view and (c) 3-D view.

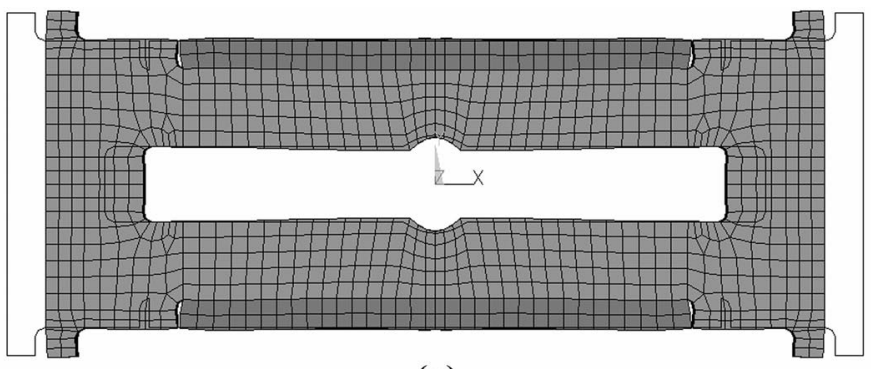

(a)

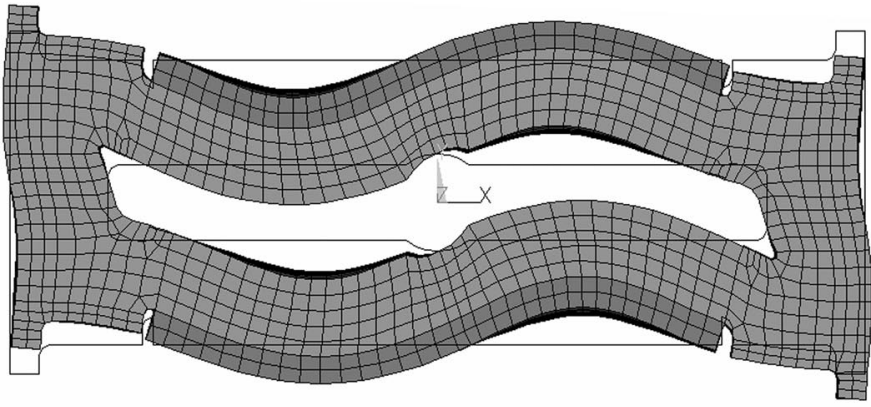

(b)

Fig. 2. Vibration modes of the stator: (a) 1st longitudinal mode and (b) 2nd bending mode.

distortion caused by the shape imbalance of the stator, four tips (for frictional components) were positioned symmetrically at the stator ends and formed in one body with the stator.

When the two pairs of electrodes are operated with same phase and resonance frequency, the first longitudinal (L1) mode is generated and the tips of the stator have a horizontal displacement component [Fig. 2(a)]. With anti-phase operation of the electrode pairs, the stator tips vibrate with vertical displacement resulting from the second bending (B2) mode [Fig. 2(b)]. By applying the two electrical sine waves to the two electrode pairs with a temporal 90 degree phase difference, the two vibration modes are excited simultaneously with phase difference of 90 degrees. As a result, an elliptical motion is excited at the tips of the stator, which drives the slider through friction force between tip and slider [4]. Note the locus at one end of stator is delayed by 180 degrees compared with that of the other end. Therefore, one of the two ends is contacting and driving the slider with anti-phase. By changing the driving phase between the two electrode pairs, the
TABle I. Fuji Ceramic's Type C-213 PZT Properties.

\begin{tabular}{ll}
\hline Property & Value \\
\hline Stiffness $\left(\times 10^{10} \mathrm{~N} / \mathrm{m}^{2}\right)$ & $c_{11}^{E}=16.7$ \\
& $c_{12}^{E}=10.5$ \\
& $c_{13}^{E}=11.0$ \\
& $c_{33}^{E}=15.4$ \\
& $c_{44}^{E}=2.5$ \\
& $c_{66}^{E}=3.1$ \\
Permittivity $\left(\times 10^{-9} \mathrm{~F} / \mathrm{m}\right)$ & $\varepsilon_{11}^{S}=6.51$ \\
& $\varepsilon_{33}^{S}=6.48$ \\
Piezoelectric stress coupling $\left(\mathrm{C} / \mathrm{m}^{2}\right)$ & $e_{13}=-2.2$ \\
& $e_{33}=19.2$ \\
Density $\left(\mathrm{kg} / \mathrm{m}^{3}\right)$ & $e_{15}=13.5$ \\
& $\rho=7800$ \\
\hline
\end{tabular}

elliptical motion of the tips changes direction, resulting in a reversal of the slider direction.

\section{Design of the Stator}

The trial motor has a simple structure and modes, but the driving tips of stator have a complicated vibrational motion. As such, a simple analytic analysis is inadequate for design. A finite element analysis (FEA) program ANSYS (ANSYS Inc., Canonsburg, PA) was used to conduct the modal and harmonic analysis of the stator and to predict the slot effect for the tip vibration motion. The FEM analysis was carried out without the bonding layer between the PZT and metal body because of the increased complication of such a model. The geometric boundary condition of the model was a free-free case. The nodes along the faces of the PZT element were merged to the electrode, which is described in detail elsewhere [10]. The model employed a complete model of hard PZT (c-213, Fuji Ceramic Co.), incorporating an anisotropic electric permittivity, piezoelectric stress coupling, and stiffness. The properties of the material relevant to the analysis are provided in Table I, where titanium, or Ti-6Al-4V (Young's modulus $114 \mathrm{GPa}$, Poisson's ratio 0.32, and density $4300 \mathrm{~kg} / \mathrm{m}^{3}$ ) was used in the modeling of stator. The model stator and parameters for FEA are illustrated in Fig. 3. 


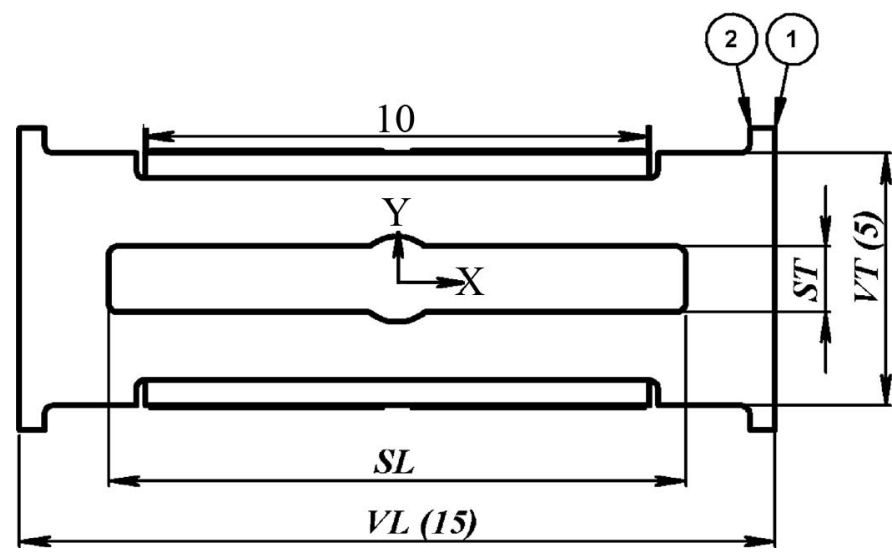

Fig. 3. The model stator and parameters for finite element analysis.

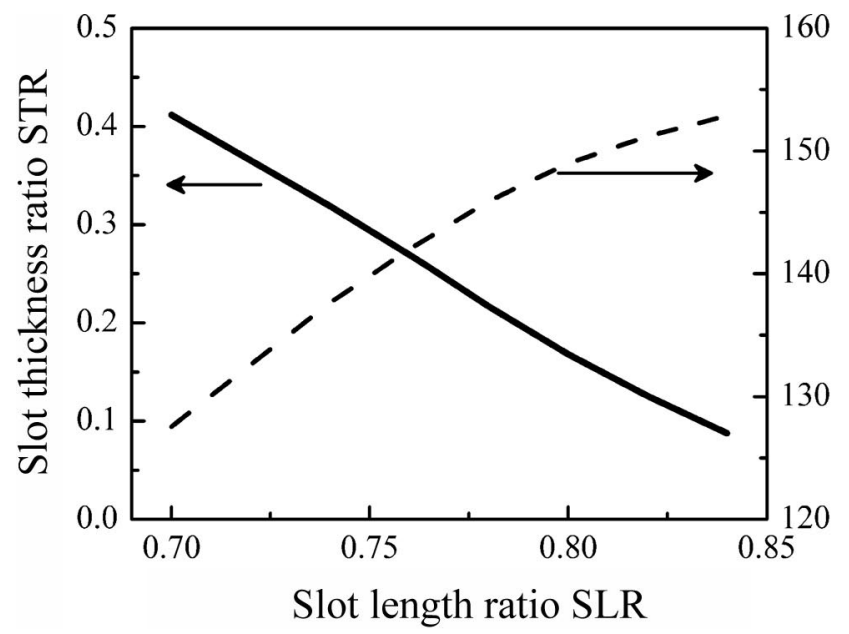

Fig. 4. The modal analysis simulation results for the effect of changing the slot dimension.

The metal body, frictional tip, and PZT element sizes were fixed at $5 \times 5 \times 15 \mathrm{~mm}, 0.5 \times 5 \times 10 \mathrm{~mm}$, and 0.5 $\times 0.5 \times 5 \mathrm{~mm}$, respectively. The slot length ratio (SLR $=\mathrm{SL} / \mathrm{VL})$ and slot thickness ratio $(\mathrm{STR}=\mathrm{ST} / \mathrm{VT})$ were changed.

To obtain a large mechanical output, the two vibration modes (L1 and B2 modes) should be tuned to have same resonance frequency as each other, and the displacement and direction of motion of driving tips should also be properly designed. Fig. 4 shows the modal analysis simulation results for different slot sizes. The two vibration modes have the same resonance frequency when the SLR and STR have a certain ratio of dimensions. Despite different slot dimensions, the stator can be designed so that the two modes have the same resonance frequency by changing the SLR and STR ratio. The matched resonance frequencies (dotted line, Fig. 4) of the two modes are increased and the STR (thick line, Fig. 4) is decreased, when the SLR is increased.

The optimal slot dimension for the trial motor was determined from the displacement results of the tip by using a harmonic analysis. Fig. 5 shows the displacement results along the driving tip (points 1 and 2, see Fig. 3) because

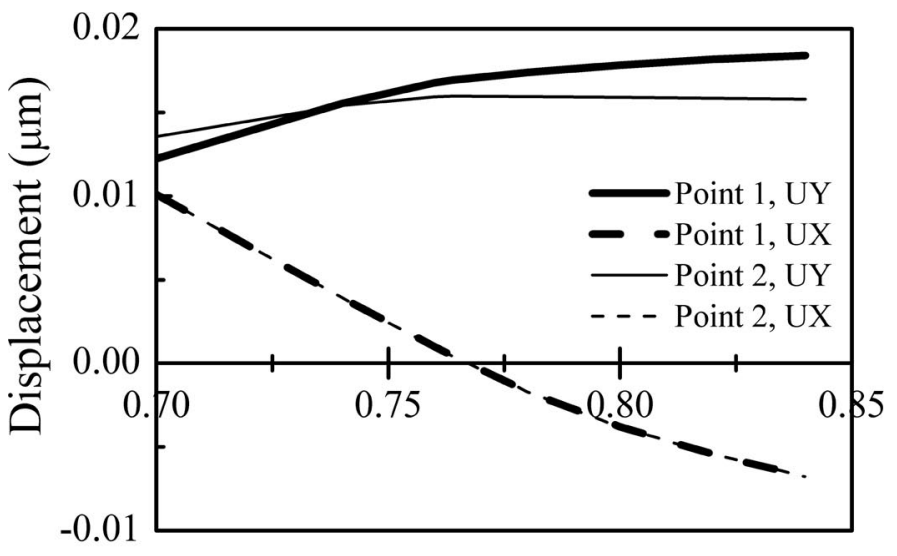

\section{Slot length ratio SLR}

Fig. 5. The displacement results versus slot dimension for the driving tip (points 1 and 2, see Fig. 3) caused by the bending vibration.

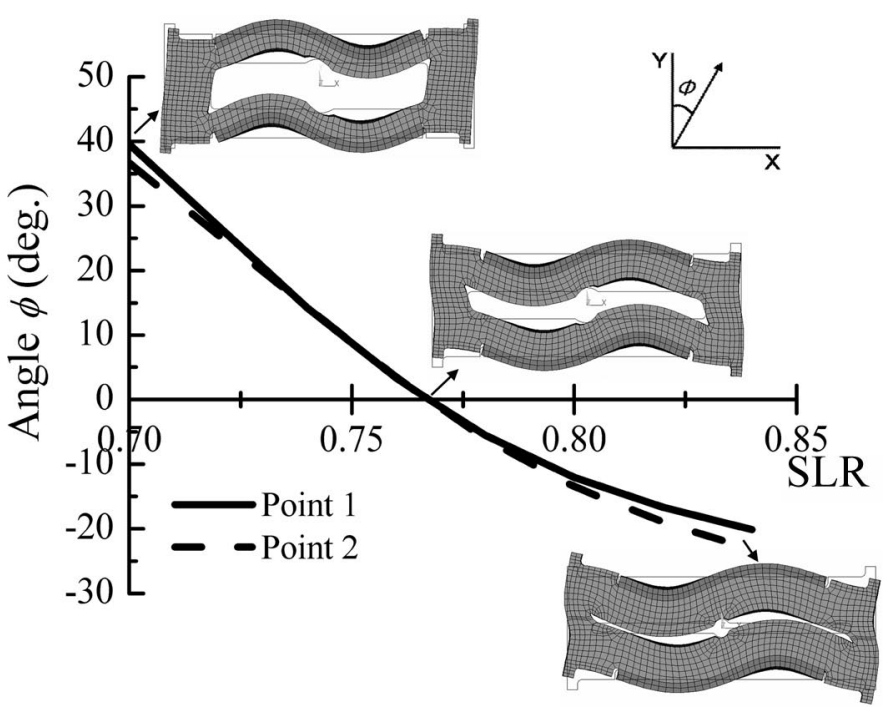

Fig. 6. The displacement angle of the driving tip surface, calculated from the data of Fig. 5.

of the bending vibration. If properly designed, the output tip will have a pure vertical displacement (UY) when the stator is excited by the bending mode vibration. The optimal slot ratio of SLR/STR was 0.764/0.26, in which the horizontal displacement (UX) of the tip was almost 0 . At this condition, the resonance frequency of L1 and B2 was $142.8 \mathrm{kHz}$ (see Fig. 4). The output tip displacement results excited by longitudinal mode vibration are omitted, but vertical motion (UY) was less than $2 \%$ of horizontal motion (UX) at the whole slot ratio within the range of this simulation works. Fig. 6 shows the displacement angle of the driving tip, calculated from the data of Fig. 5, and also shows the representative vibration shapes with three different slot ratios to better understand the slot effects for the tip vibration. Although the slot ratios of three shapes were adjusted so that the resonance frequencies of L1 and B2 modes were matched, the tip motion was quite different with the slot shapes. Except for the optimum 


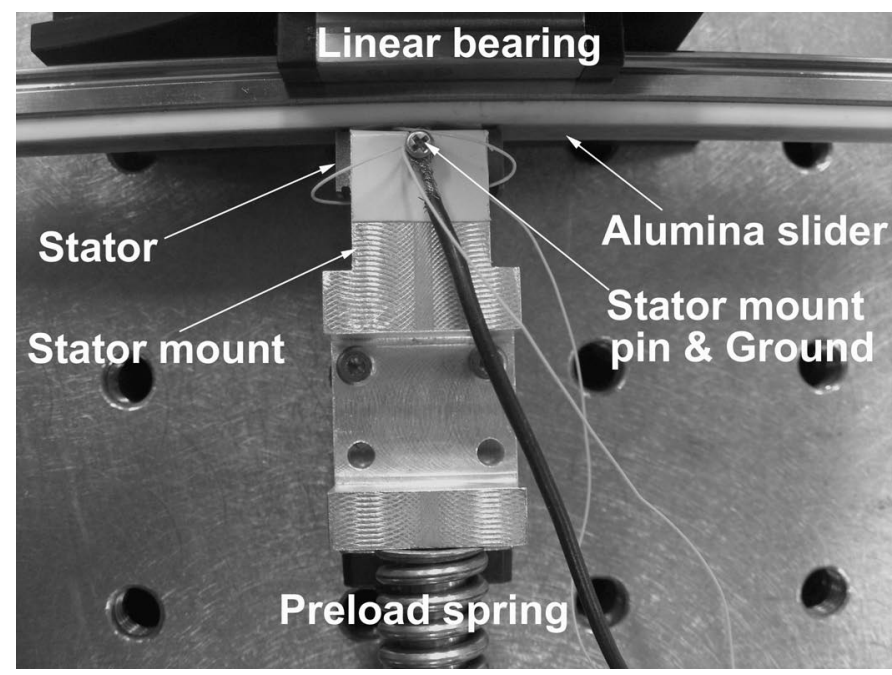

Fig. 7. The experimental setup to measure the operation characteristics of the motor.

slot dimension, the end tips of the stator have longitudinal coupling displacement caused by bending vibration.

\section{EXPERIMENTAL SETuP}

The experimental setup to measure the operational characteristics of the motor is shown in Fig. 7. The stator is supported by a pin through the centrally placed mount hole in which the two vibrations have a common node, providing a method to hold it without disturbing the vibrations. The stator mount pin was grounded. A 130-mm-long linear bearing (RSR-7, THK Corporation, Shinagawa, Japan) was used as the slider and a mirrorpolished alumina friction plate was bonded on the surface of the linear bearing rail. The weight of the slider moving parts, including the alumina plate, was $35 \mathrm{~g}$. The preload between the slider and the stator was provided and changed by changing the coil spring length.

\section{Characteristics of the Motor}

The admittance characteristics of the trial motor are measured at low voltage using an impedance analyzer (4294A Agilent, Santa Clara, CA). Fig. 8 shows the measured admittance and phase characteristics with respect to frequency. To measure the in-phase drive admittance, all four input electrodes were connected to the High terminal and the metal body of stator was connected to the Low terminal of the test fixture of the impedance analyzer. However, to measure the anti-phase drive characteristics, one electrode pair [sine PZTs, Fig. 1(c)] was connected to the High and the other pair [cosine PZTs, Fig. 1(c)] was connected to the Low. The in-phase driving resonance frequency was $143.25 \mathrm{kHz}$ and the anti-phase drive resonance frequency was $143.17 \mathrm{kHz}$.

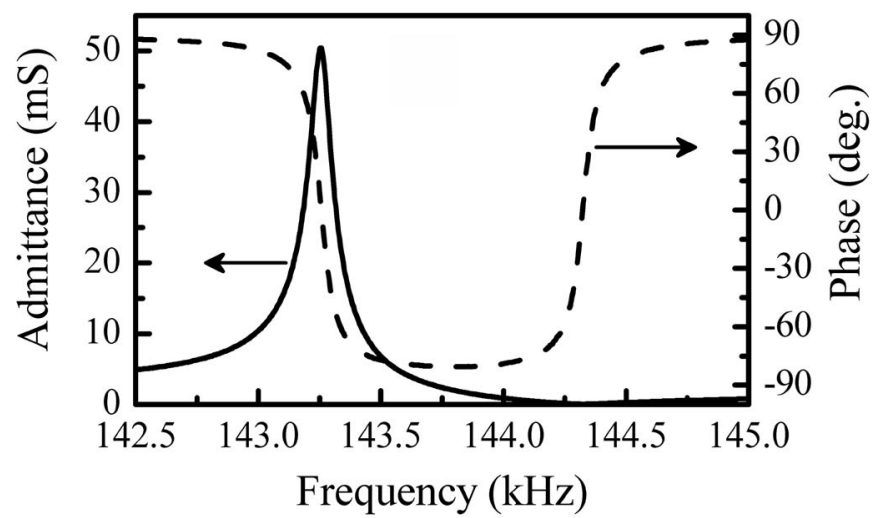

(a)

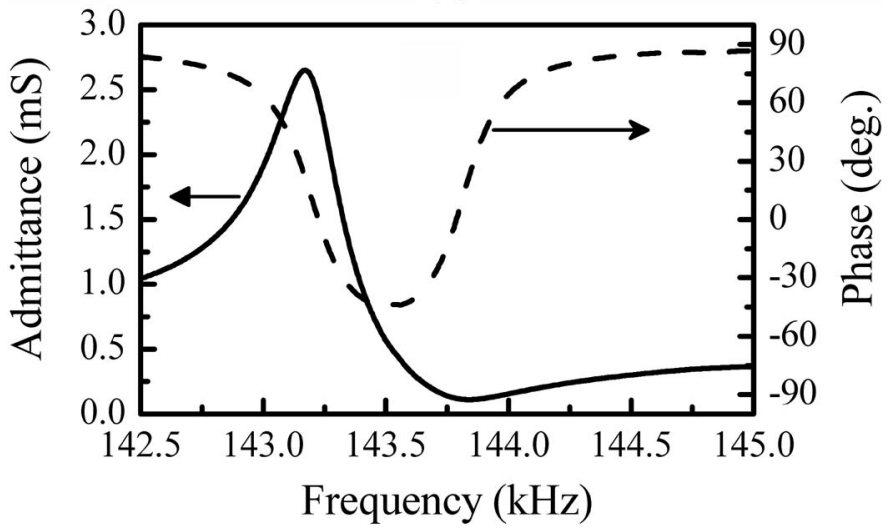

(b)

Fig. 8. Admittance and phase characteristics of the stator with respect to the frequency: (a) in-phase drive and (b) anti-phase drive.

The vibration velocity of the stator and driving velocity of the slider were measured by using an LDV (AT0023+0070, Graphtec, Yokohama, Japan) [10], [11]. Fig. 9 shows the two contact tips' displacement motion measured by using an LDV at $143.25 \mathrm{kHz}$ and $10 \mathrm{~V}_{0-\mathrm{p}}$ while driving both electrode pairs of the stator with a $90^{\circ}$ phase difference. These experimental results show that the elliptical motions of the tip were well matched to the results of FEA calculations.

The driving characteristics of the motor were calculated from the measured velocity of the slider with respect to time, as shown in Fig. 10. From the velocity data and the mass of the slider, the force that the motor can deliver was calculated at every point on the rise curve using the method developed by Nakamura [12]. The load characteristics of the motor were measured at the driving voltage of $70 \mathrm{~V}_{0-\mathrm{p}}$ and the driving frequency of $143.3 \mathrm{kHz}$, which is near the resonance frequency of the stator. The preload was changed to $2.5,4,10$, and $15 \mathrm{~N}$. The driving velocity and force curves are shown in Fig. 11. In general, with an increase in the preload, the maximum sliding force also increased. We also note that the maximum sliding force at a preload of $15 \mathrm{~N}$ was almost same as that with a preload of $10 \mathrm{~N}$. The maximum driving force was saturated at the preload of 2.5 and $4 \mathrm{~N}$, because of the limitation of friction force determined by pre-load and the frictional coefficient 


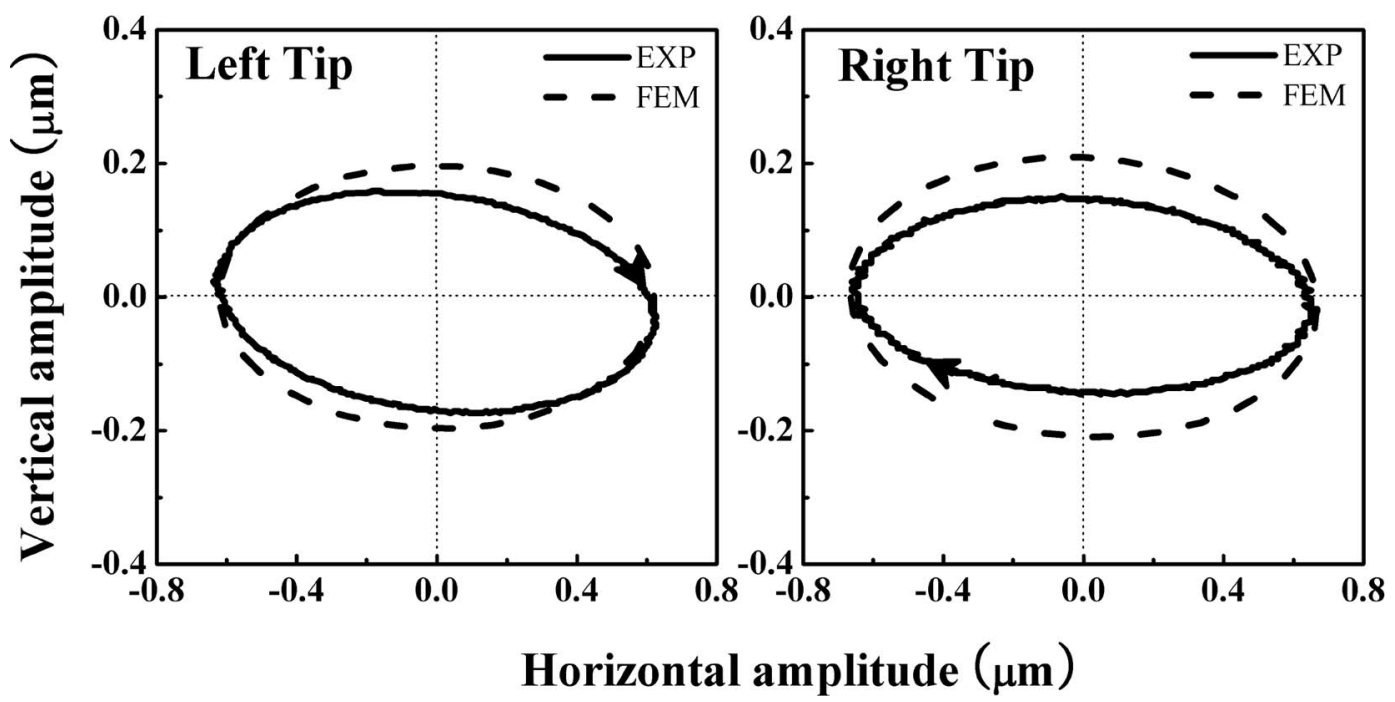

Fig. 9. Left and right tips' vibration motion at $10 \mathrm{~V}_{0-\mathrm{p}}$ and $143.25 \mathrm{kHz}$.

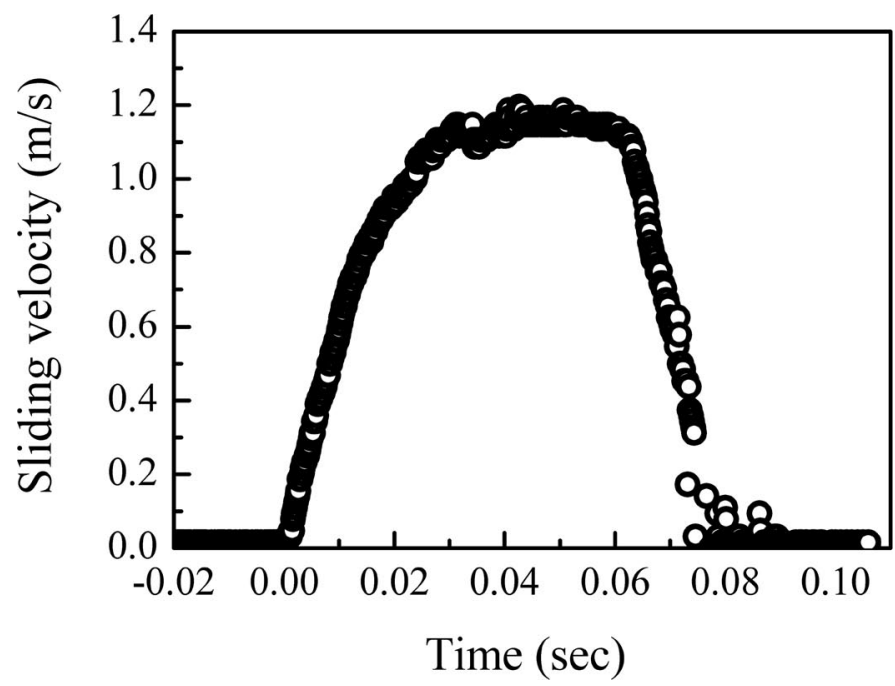

Fig. 10. The measured transient response of the motor velocity with respect to time by the $\mathrm{LDV}$.

[4]. The maximum sliding velocity decreased slightly with an increase in preload above $4 \mathrm{~N}$. At a preload of $2.5 \mathrm{~N}$, however, the sliding velocity was considerably lower when compared with that of higher preloads, a result observed in other actuators [10], [13]. This low velocity could be caused by the contact stiffness effect [4]. Note that as the preload is changed, the resonance frequency is also changed, because the contact stiffness between the driving tip and slider directly affects the resonance frequency of the stator. At a low-preload condition, the resonance frequency of the bending mode was lower than that of the longitudinal mode. However, the resonance frequency of two modes could be matched at a higher preload condition, as the mode stiffness of the bending mode is more influenced by the preload than is that of the longitudinal mode [4]. For this trial linear motor, with a weight of $1.6 \mathrm{~g}$, we quote a no-load velocity of $1.25 \mathrm{~m} / \mathrm{s}$ at the driving voltage of $70 \mathrm{~V}_{0-p}$ and a preload of $4 \mathrm{~N}$.

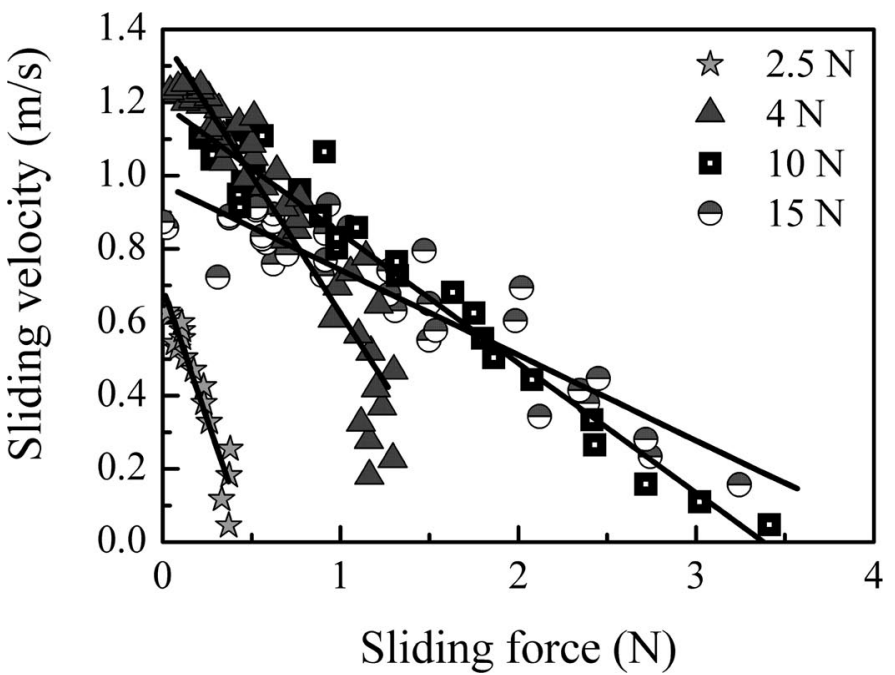

Fig. 11. Load characteristics of the motor at $70 \mathrm{~V}_{0-\mathrm{p}}$ and $143.3 \mathrm{kHz}$.

Fig. 12 shows the velocity-force and mechanical output power characteristics of both directions at a preload of $10 \mathrm{~N}$. Under this preload condition, a maximum driving velocity of $1.12 \mathrm{~m} / \mathrm{s}$ and a maximum driving force of $3.4 \mathrm{~N}$ were achieved. The maximum mechanical output power of $1.1 \mathrm{~W}$ was obtained at the force of $1.63 \mathrm{~N}$ and the velocity of $0.68 \mathrm{~m} / \mathrm{s}$. The mechanical output power per unit weight was $688 \mathrm{~W} / \mathrm{kg}$. The motor in this study is compared with selected recent linear motors based on the construction method, as shown in Fig. 13. The mechanical output power and the weight of the motor are calculated from the published works. The mechanical output power of piezoceramic motors and bonded metal/piezoceramic motors, including the motor in this study, are smaller than that of BLT-type motors. However, the output power density (output power/unit weight) of these types is large when compared with a BLT-type motor because the weight of the stator is much smaller than BLT-type motors. This results show that a small-size motor is more favorable in 


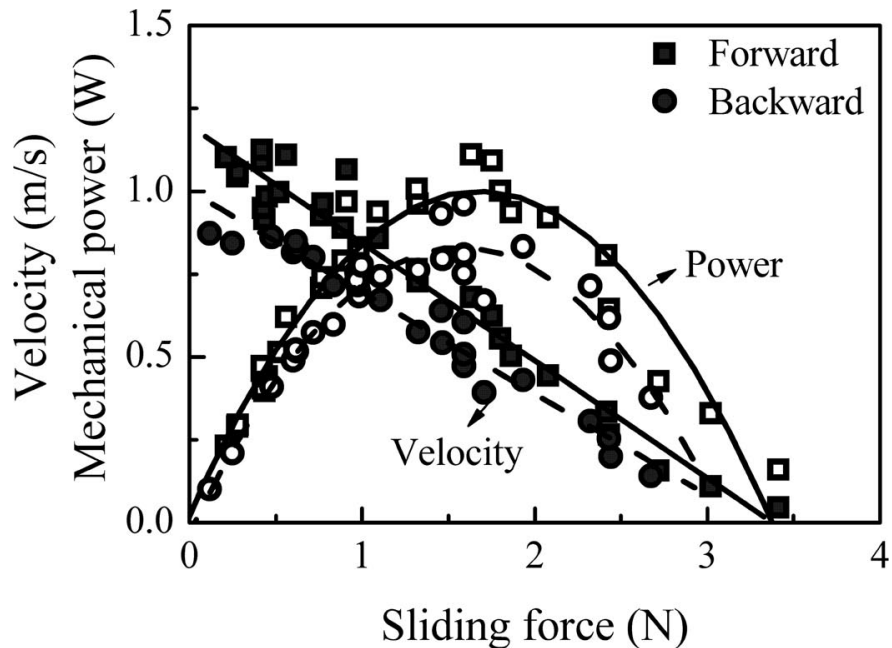

Fig. 12. Load characteristics of the motor at the preload of $10 \mathrm{~N}, 70 \mathrm{~V}_{0-\mathrm{p}}$, and $143.3 \mathrm{kHz}$.

output power density. The mechanical output power per unit weight of the motor in this study is roughly 10 times larger than the ceramic motor by Nanomotion (model HR1, stator size of $3 \times 7.5 \times 29 \mathrm{~mm}$ ).

In this study, a higher motor performance than previous motors was achieved by adopting titanium (Ti64) as the stator material. Titanium has a lower density and a higher transfer efficiency of ultrasonic vibration energy than PZT and phosphor bronze, which were used for the stator material of the Nanomotion [5] and Rho motors [14], respectively. In addition, by using the double driving tips attached to the position of both the highest bending and longitudinal displacement position, the maximum motor performance is increased as the driving force of the motor is transferred to the slider two times per cycle of vibration. Moreover, the bending vibration modified by the slot structure decreased the undesirable longitudinal coupling displacement of the end tips so that the elliptical motion of the two driving tips could be properly operated.

\section{Conclusion}

A novel ultrasonic micro linear motor that uses the 1st longitudinal and the 2nd bending modes, derived from a bar-type stator with rectangular slot cut through the stator length was proposed, designed, and tested. The slotstructure plays an important role in the motor design, which can be used not only to tune the two vibration modes to the same resonance frequency but also to decrease the undesirable longitudinal coupling displacement caused by the bending vibration at the end of a stator. By using finite element analysis, the optimal slot dimension to improve the motion for the driving tips was determined. The trial linear motor, with a weight of $1.6 \mathrm{~g}$, was given a peak no-load velocity of $1.25 \mathrm{~m} / \mathrm{s}$. Under the preload of $10 \mathrm{~N}$, the maximum driving velocity of $1.12 \mathrm{~m} / \mathrm{s}$ and the maximum driving force of $3.4 \mathrm{~N}$ were achieved. The maxi-

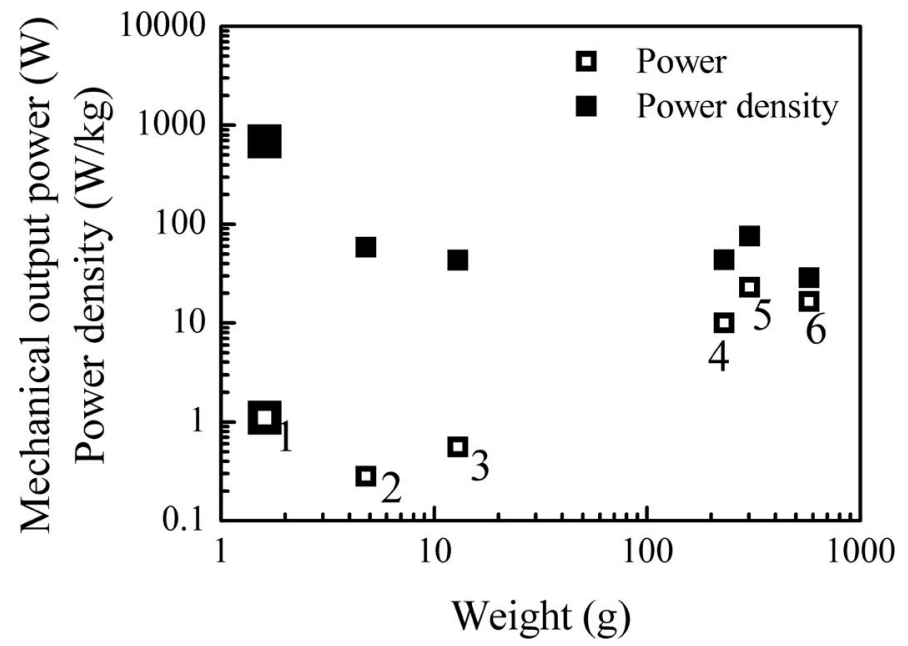

Fig. 13. A comparison of the mechanical output power and power density versus weight for several linear ultrasonic motors: (1) the motor in this paper, (2) piezoceramic plate motor (Nanomotion) [5], (3) bonded metal/piezoceramic motor (L1B4 modes) by Rho et al. [14], (4) BLTtype motor (ø20) [3], (5) BLT-type V-shape motor (ø20) [15], and (6) BLT-type motor $(\varnothing 40)[4] . \varnothing=$ diameter of stator.

mum mechanical output power of $1.1 \mathrm{~W}$ was obtained at the force of $1.63 \mathrm{~N}$ and the velocity of $0.68 \mathrm{~m} / \mathrm{s}$. The mechanical output power per unit weight was $688 \mathrm{~W} / \mathrm{kg}$; this value offers the potential for use in microrobotics and bio-medical applications.

\section{ACKNOWLEDGMent}

The authors wish to thank the Monash University Engineering Workshop staff.

\section{REFERENCES}

[1] T. Morita, M. K. Kurosawa, and T. Higuchi, "Cylindrical micro ultrasonic motor utilizing bulk lead zirconate titanate (PZT)," Jpn. J. Appl. Phys., vol. 38, no. 5B, pp. 3347-3350, 1998.

[2] K. Uchino, "Piezoelectric actuator 2006: Expansion from IT/robotics to ecological/energy applications," J. Electroceram., vol. 20, pp. 301-311, Aug. 2008.

[3] W.-S. Kim, C.-H. Yun, and S.-K. Lee, "Nano positioning of a high power ultrasonic linear motor," Jpn. J. Appl. Phys., vol. 47, no. 7, pp. 5687-5692, 2008.

[4] C.-H. Yun, T. Ishii, K. Nakamura, S. Ueha, and K. Akashi, "A high power ultrasonic linear motor using a longitudinal and bending hybrid bolt-clamped Langevin type transducer," Jpn. J. Appl. Phys., vol. 40 , no. 5B, pp. $3773-3776,2001$.

[5] J. Zumeris, "Ceramic motor," U.S. Patent 5453653, Sep. 26, 1995.

[6] K. Spanner, "Survey of the various operating principles of ultrasonic piezomotors," in Proc. 10th Int. Conf. New Actuators, 2006.

[7] Y. Ming, B. Hanson, M. C. Levesley, P. G. Walker, and K. G. Watterson, "Amplitude modulation drive to rectangular-plate linear ultrasonic motors with vibrators dimensions $8 \mathrm{~mm} \times 2.16 \mathrm{~mm} \times 1$ mm," IEEE Trans. Ultrason. Ferroelectr. Freq. Control, vol. 53, no. 12, pp. 2435-2441, 2006.

[8] Y. Ming, Z. Meiling, R. C. Richardson, M. C. Levesley, P. G. Walker, and K. Watterson, "Design and evaluation of linear ultrasonic motors for a cardiac compression assist device," Sens. Actuators A, vol. 119, no. 1, pp. 214-220, 2005.

[9] C. Lu, T. Xie, T. Zhou, and Y. Chen, "Study of a new type linear ultrasonic motor with double-driving feet," Ultrasonics, vol. 44, suppl. 1, pp. 585-589, Dec. 2006. 
[10] J. Friend, Y. Gouda, K. Nakamura, and S. Ueha, "A simple bidirectional linear microactuator for nanopositioning-The "Baltan" microactuator," IEEE Trans. Ultrason. Ferroelectr. Freq. Control, vol. 53, no. 6, pp. 1160-1168, 2006.

[11] J. Friend, K. Nakamura, and S. Ueha, "A traveling-wave, modified ring linear piezoelectric microactuator with enclosed piezoelectric elements-The "scream" actuator," IEEE Trans. Ultrason. Ferroelectr. Freq. Control, vol. 52, no. 8, pp. 1343-1353, 2005.

[12] K. Nakamura, M. Kurosawa, H. Kurebayashi, and S. Ueha, "An estimation of load characteristics of an ultrasonic motor by measuring transient responses," IEEE Trans. Ultrason. Ferroelectr. Freq. Control, vol. 38, no. 5, pp. 481-485, 1991.

13] J. Friend, J. Satonobu, K. Nakamura, S. Ueha, and D. S. Stutts, "A single-element tuning fork piezoelectric linear actuator," IEEE Trans. Ultrason. Ferroelectr. Freq. Control, vol. 50, no. 2, pp. 179 186, 2003.

[14] J.-S. Rho, B.-J. Kim, C.-H. Lee, H.-W. Joo, and H.-K. Jung, "Design and characteristic analysis of L1B4 ultrasonic motor considering contact mechanism," IEEE Trans. Ultrason. Ferroelectr. Freq. Control, vol. 52, no. 11, pp. 2054-2064, 2005.

[15] M. Kuribayashi Kurosawa, O. Kodaira, Y. Tsuchitoi, and T. Higuchi, "Transducer for high speed and large thrust ultrasonic linear motor using two sandwich-type vibrators," IEEE Trans. Ultrason. Ferroelectr. Freq. Control, vol. 45, no. 5, pp. 1188-1195, 1998.

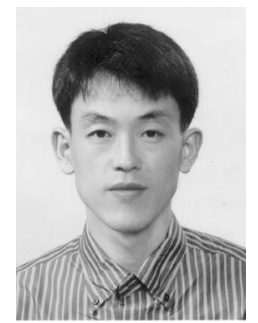

Cheol-Ho Yun received the B.Eng. and M.Eng. degrees in inorganic material engineering from the Chonnam National University, Gwangju, Korea, in 1996 and 1998, respectively, and the Ph.D. degree in advanced applied electronics in 2002 from the Tokyo Institute of Technology, Tokyo, Japan. He was a postdoctoral fellow at Tokyo Institute of Technology, from 2002 to 2003. From 2004 to 2008 , he worked as a senior researcher for the Korea Institute of Industrial Technology, Korea. Since 2009, he has been a research fellow at the Micro/Nanophysics Research Laboratory, Monash University, Clayton, Victoria, Australia. His current research interests include high-power ultrasonic actuators, micro actuators, and PZT thin films and their applications.

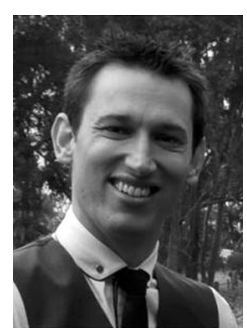

Brett Watson is currently undertaking his Ph.D. degree in mechanical engineering at Monash University as part of the MicroNanophysics Research Laboratory. He received his Bachelor of Engineering (Mechanical) from Curtin University in 2000. His research interests are in motors, actuators, and propulsion systems for biomedical micro-robotic applications. His paper on a piezoelectric micro-motor for in vivo swimming microbots at AOTULE 2008 was highly commended. He is a member of the Golden Key Honour Society and currently has a patent application in progress.

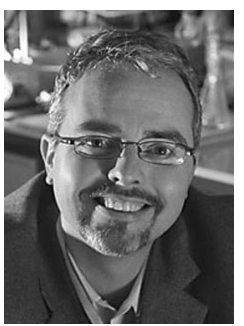

James Friend joined Monash University in late 2004, and co-founded and co-directs the $\$ 6.5$ million MicroNanophysics Research Laboratory with clean room and biolab, a current staff of three academics, three post-doctorates and thirteen Ph.D. students. He is a Professor in the Department of Mechanical and Aerospace Engineering and Associate Dean, Research, of the Faculty of Engineering at Monash University, with research interests in micro/nanodevices for biomedical applications. He is the associate editor of Biomicrofluidics, a member of IEEE, ASME, Golden Key, the Lifeboat Foundation for the safe uses of nanotechnology, and a committee member of IEEE Nanotechnology for Biology. He has over one-hundred peer-reviewed publications, with five book chapters, sixty-two peer-reviewed journal papers, and sixteen patents and patent applications. He received excellence in teaching and early career researcher awards from the Monash Faculty of Engineering in 2006 and 2008, respectively, a Future Leader award from the Davos Future Summit in Sydney in 2008, and was awarded membership in the Top 100 emerging leaders of Australia by Microsoft and The Australian newspaper in 2009.

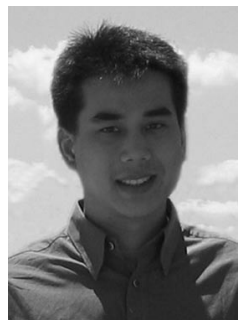

Leslie Yeo received his Ph.D. degree from Imperial College London in 2002, for which he was awarded the Dudley Newitt prize for a computational/theoretical thesis of outstanding merit. He is currently an Australian Research Fellow and Associate Professor in the Department of Mechanical \& Aerospace Engineering and Co-Director of the Micro/Nanophysics Research Laboratory at Monash University, Australia. Prior to joining Monash University, he was a Mathematical Modeller at Det Norske Veritas UK and a postdoctoral research associate in the Department of Chemical \& Biomolecular Engineering at the University of Notre Dame, Notre Dame, IN. Dr. Yeo was the recipient of the 2007 Young Tall Poppy Science Award from the Australian Institute for Policy \& Science "in recognition of the achievements of outstanding young researchers in the sciences including physical, biomedical, applied sciences, engineering and technology," and both the Dean and Vice-Chancellor's awards for excellence in early career research. His work on microfluidics has been featured widely in the media, for example, on the Australian Broadcasting Corporation's science television program Catalyst, 3RRR radio broadcast, and in various articles in The Economist, New Scientist, The Washington Times, The Age, and The Sydney Morning Herald, in addition to being highlighted in Nature and Science. Dr Yeo is co-author of the book Electrokinetically Driven Microfluidics 83 Nanofluidics (Cambridge University Press), and the author of over 90 research publications and over 15 patent applications. $\mathrm{He}$ is also the Editor of the American Institute of Physics journal Biomicrofluidics. 